\title{
Collective Intentionality
}

\author{
PREPRINT \\ in The Routledge Companion to the Philosophy of Social Science, \\ ed., Lee McIntyre and Alex Rosenberg, New York: Routledge (2016) \\ Marija Jankovic and Kirk Ludwig
}

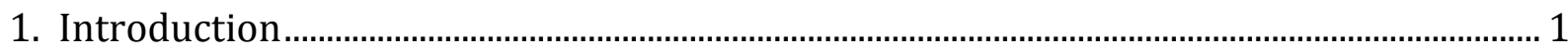

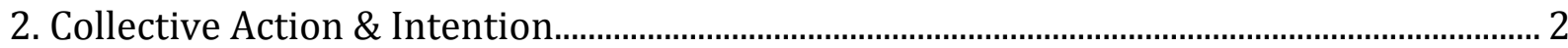

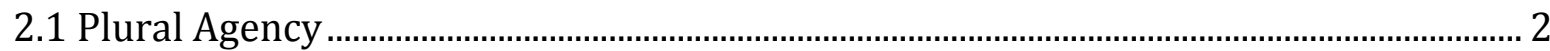

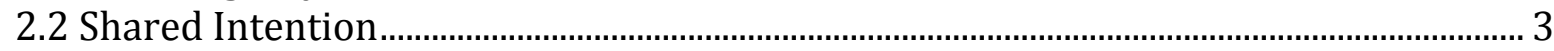

3. The role of collective intentionality in our understanding of the social................................ 5

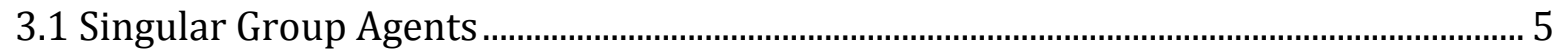

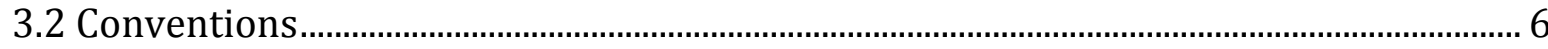

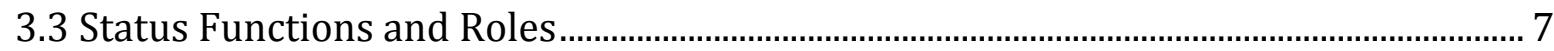

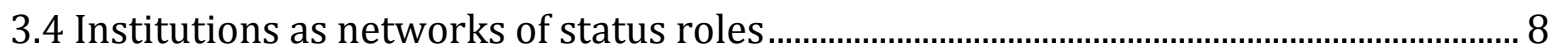

3.5 Proxy Agency in Institutional Action............................................................................... 9

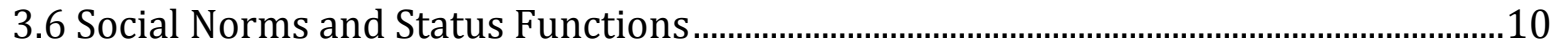

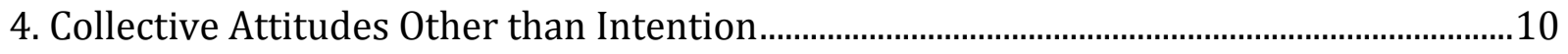

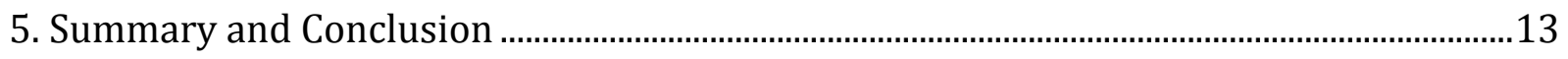




\section{Introduction}

Intentionality is the property of being about, or directed at, something. Your belief that Athens is the capital of Greece is about Athens being the capital of Greece. Your desire for another cup of coffee is about your having a cup of coffee. A state with intentionality is an intentional state. Paradigmatic intentional states are propositional attitudes such as beliefs, intentions, desires, and hopes. They have a psychological mode (belief, intention, desire, hope, etc.) and a propositional content (e.g., that Athens is the capital of Greece), which may match or fail to match the world.

Collective intentionality concerns intentionality in the social context. Its distinctive focus is the conceptual and psychological features of joint actions and attitudes, their relations to individual actions and attitudes, and the implications for the nature of social groups and their functioning. It subsumes the study of collective action, responsibility, reasoning, intention, emotion, phenomenology, knowledge, trust, rationality, responsibility, cooperation, and competition, and how these underpin social practices, norms, conventions, institutions and ontology. Collective intentionality is a growing interdisciplinary area of research with contributions from philosophy, psychology, political science, legal theory, linguistics, cognitive science, sociology, anthropology, and computer science.

In this chapter, we focus on collective action and intention, and their relation to conventions, status functions, norms, institutions, and shared attitudes more generally. Collective action and shared intention play a foundational role in our understanding of the social.

The three central questions in the study of collective intentionality are:

(1) What is the ontology of collective intentionality? In particular, are groups per se intentional agents, as opposed to just their individual members?

(2) What is the psychology of collective intentionality? Do groups per se have psychological states, in particular propositional attitudes? What is the psychology of the individuals who participate in collective intentional behavior? What is special about their participatory intentions, their we-intentions, as they are called (Tuomela and Miller 1988), as opposed to their I-intentions?

(3) How is collective intentionality implicated in the construction of social reality? In particular, how does the content of we-intentions and the intentional activity of individual agents create social institutions, practices and structures?

Section 2 discusses collective action and shared intention in informal groups. Section 3 discusses mechanisms for constructing institutional structures out of the conceptual and psychological resources made available by our understanding of informal joint intentional action. It extends the discussion of collective action and intention to institutional groups, such as the Supreme Court, and explains how concepts of such organizations are constructed out of the concepts of a rule, convention, and status function. Section 4 
discusses collective attitudes beyond intention. Section 5 is a brief summary and conclusion.

\section{Collective Action \& Intention}

\subsection{Plural Agency}

What is the difference between individual and collective action? We begin with actions attributed to informal groups picked out using plural referring terms. We call these plural group agents, without implying they are agents per se. We can sharpen our initial question by asking what the difference is between the truth conditions for [1] and [2].

[1] I moved a bench

[2] We moved a bench

The parallel forms of [1] and [2] seem to commit us to the subject in [2], a group, being the agent of a bench moving, and so to group agents per se. However, initial appearances are misleading. To see this, we bring to bear the event analysis of singular action sentences like [1] (Davidson 2001) on the distributive/collective ambiguity of plural action sentences like [2] (Ludwig 2007a, 2010).

On the event analysis, [1] says its subject is the agent of an event. For present purposes, we ignore tense and some details about how verbs select determinate forms of the agency relation (Ludwig 2007a; 2016a, ch. 6). We analyze [1] as in [1a] (where ' $(\exists e)$ ' means 'there is an event $e$ such that').

[1a] ( $\exists e)(\mathrm{I}$ am an agent of $e$ and $e$ is a bench's moving and only I am an agent of $e$ )

[2] can be read distributively or collectively. Read distributively, it means that each of us moved a bench, as in [1d]. The collective reading derives from giving each of us narrow scope with respect to the event quantifier. [2] says that there is some event of which each of us is an agent and no one else is (thus adjusting the requirement of sole agency also) and it is a bench's moving, as in [1c].

[1d] [Each $x$ of us] $(\exists e)(x$ is an agent of $e$ and $e$ is a bench's moving and only $x$ is an agent of $e$ )

[1c] ( $\exists e)$ [Each $x$ of us] $(x$ is an agent of $e$ and $e$ is a bench's moving and only we are agents of $e$ )

The difference lies (to a first approximation) in whether we are saying each of us did something to bring about an event of a certain type or that there is an event of a certain type each of us contributed to bringing about. On this account of the collective reading of plural action sentences, then, we have no need for group agents per se. We still refer to groups, but only their members are agents. 


\subsection{Shared Intention}

We act together intentionally when we successfully execute a shared intention. We attribute shared intentions with sentences like [3].

[3] We intend to move a bench.

[3] has a distributive reading, [3d].

[3d] Each of us intends (himself) to move a bench.

Our interest lies in the collective reading on which we intend to move a bench together. On the collective reading, [3] attributed a shared intention to move a bench. Some authors take shared intentions to be states of groups as such (Velleman 1997; List and Pettit 2011; Pettit 2003; Tollefsen 2002; Copp 2006; Stoutland 1997, 2008). But, prima facie, if we don't need group agents for collective action, we don't need them as subjects of shared intention (we turn to institutional agency below). We therefore treat the subject of [3] distributively even on the collective reading, as in [3c].

[3c] Each of us intends that we move a bench together.

On this view, for us to share an intention is for each to have an appropriate intention to participate in our doing something, a we-intention as opposed to an I-intention. The problem of shared intention then reduces to the problem of we-intentions.

There are number of competing analyses of we-intentions.

John Searle $(1990,1995,2010)$ holds that we-intentions are intentions to bring about a joint action by way of an individual contribution. (Searle is often said to hold that weintending is primitive, but Ludwig argues that this is a misinterpretation (2007b).) This isn't sufficient, as each of us could intend to bring it about that we do something together but have it in mind to trick the other into doing his part. For example, suppose that each of us intends to go to NYC with the other and wants to take the more expensive fast train, but thinks that the other intends to take the slower train. Each could then plan to get the other to board the fast train by tricking her into thinking that the train currently on the platform is the slow one (by moving her clock forward). In this case, though each of us intends that we go to NYC by way of something she does, we don't share an intention to go to NYC.

Margaret Gilbert (2006) explains shared intention in terms of the primitive notion of joint commitment. When we share an intention, we jointly commit to doing something (e.g., moving a bench) as a body. This joint commitment entails sui generis obligations of each party to do her part. These obligations are owed to the other parties and cannot be unilaterally rescinded. The parties, however, need not have any particular individual intentions (contra Searle, Bratman, Ludwig). If Gilbert is right, all joint intentional action involves norms internal to its nature. However, while it is widely accepted that obligations 
with the content Gilbert describes typically accompany collective intention, it is controversial whether they necessarily accompany it (Bratman 1999b).

David Velleman (1997) has argued that shared intentions are realized in interlocking speech acts - one person saying, e.g., I will if you will, and the other saying I will-which jointly cause their own conditions of satisfaction. But this cannot cover all cases of shared intention. Furthermore, it is motivated by the worry that if each group member intends that they do something, then counter-intuitively each thinks he will determine what the others do-which has been shown to be incorrect (Bratman 1999a). Accounts of weintentions have also been advanced in terms of a special sort of reasoning (team reasoning) leading to joint action (Gold and Sugden 2007). But team reasoning, although directed at a group interest, is reasoning of individuals who are deciding strategically in light of what others will do. It is therefore compatible with their having only I-intentions directed at that group interest. Raimo Tuomela (Tuomela and Miller 1988; Tuomela 2005, 2013) has championed a conception of we-intentions as intentions to do one's part in the group's doing something together, under conditions of mutual belief about others in the group so intending and the conditions for a reasonable chance of success being in place. However, Tuomela notes specifically (2005) that by 'the group's doing something together' he means 'the group's doing something together intentionally' (contra Searle's (1990) interpretation). Consequently, he does not aim to give a fully reductive account of we-intentions since the analysis uses a concept related to the concept it analyzes in giving the content of the intention.

In contrast, Michael Bratman's influential account of we-intentions gives a reductive account of their content $(1992,1993,1999 a, 1999 b, 2006,2014)$. He holds that a weintention is an intention of an individual that a group she belongs to do something by way of meshing (i.e., compossible) subplans associated with each member's intention that the group do it. A virtue of this account is that it captures the idea that joint intentional action is fundamentally collaborative. This is implied by the requirement that each member of the group intend that the subplans they associate with their intentions mesh. This element rules out the case of mutually intended deception toward the same goal considered above. In this case, each intends that we go to NYC in part by way of the other's intentions that we go. But each intends to deceive the other into taking the fast train, rather than to arrive at compatible subplans. An important question is how much mesh of subplans is required (Ludwig 2015a): all seems too strict (one can intend not to be fully cooperative, but cooperative enough to get the job done); some seems not strict enough (we can intend to take advantage of the others' plans up to a point only).

A similar reductive approach, motivated by semantic considerations, is Ludwig's (2007a, 2016a). He understands we-intentions as intentions to make a contribution to the group doing a particular thing in accordance with a shared plan (which need not be given ahead of time), where the shared plan incorporates a margin for error around a canonical plan conception. Modest deviations from the canonical plan are compatible with the group carrying out the plan successfully. This helps avoid the problem of degree of mesh that Bratman's account faces. It also rules out cases of mutual deception because in that case the agents do not intend there be a shared plan in accordance with which they both act. 
Both accounts accommodate joint intentional action involving competition. For the participants cooperate in bringing about an action type that specifies that they compete within a framework of rules to achieve an end that not all can attain.

Other important accounts, which we lack space to discuss, are those of Seumas Miller (2001) in terms of intentions directed at shared ends, and Sara Chant and Zach Ernst (2008) in terms of rationality conditions for joint action.

\section{The role of collective intentionality in our understanding of the social}

Joint intentional action is one of the basic building blocks for institutional reality. By institutional reality, we mean both institutions understood as networks of interconnected roles (that is, organizations), like the Supreme Court, and social customs or practices, like tipping, shaking hands or speaking a language. Due to space constraints, we discuss in detail only the former. Institutions as organizations (henceforth 'institutions') we explain using the concepts of a status function and status role. These, in turn, we explain using the concepts of a constitutive rule and a convention. Status roles come with powers, rights, duties, and responsibilities. Many social norms can be understood as grounded in assignments of status functions and roles. The structure of status roles in an organization is particularly relevant to distributing individual responsibility when the group is held to blame (morally or legally) for its actions.

We begin by contrasting the language of institutional agency with that of informal (plural) group agency. Then we discuss conventions. Next we explain status functions and roles. We use these to explain the structure of institutions, and one sort of social norm.

\subsection{Singular Group Agents}

Institutional action sentences typically employ grammatically singular subject terms, as in [4].

[4] The Supreme Court reversed its 1896 ruling that segregation is constitutional in Brown vs. Board of Education in 1954.

Call groups denoted with grammatically singular terms singular group agents (again, without implying they are agents per se). Singular group agents appear to differ from plural group agents in several important respects.

(a) Singular group agents can perform actions that individuals cannot, even in principle.

(b) Singular group agents retain their identity through changes in membership.

(c) Singular group agents could have had different members than they do.

(d) Membership in singular group agents is socially constructed.

(e) Singular group agents often act through the agency of some subgroup, or individual member, as in the case of a spokesperson, so that the expression of group agency seems not to depend on all its members contributing to what it does. 
These differences may suggest that we think of singular group agents (institutions in particular) as genuine group level agents.

However, as above, initial impressions are misleading (Ludwig 2014a; 2017, ch. 3-5). First, many singular group action sentences, like [5], have both a distributive and collective reading.

[5] The Supreme Court went to lunch.

[5] may mean that the Supreme Court went to lunch together, or that they went to lunch separately. This parallel with plural group action sentences supports the multiple agents analysis of the collective reading. Second, when singular group action sentences do not have a distributive reading, as for [4], it is because the verb expresses an action type that by definition requires contributions from multiple agents (this explains (a)). This is unrelated to the grammatical number of the subject. The same point applies to 'We met in the library'. Neither of us could do this alone, even in principle. This is because meeting requires at least two people. The same goes for Supreme Court rulings.

Third, (b) and (c) are explained by (d). To be a member of the Supreme Court is to accept an institutional role (on which more below) by being nominated by the President, accepting the nomination, and being confirmed by the Senate. This is different from merely being arbitrarily grouped with other things. Most importantly, it is a time-indexed condition, for the status that suffices for membership can be removed (by resigning, e.g.), and assigned to someone else. This allows us to talk about the members of the group at a time: when the group acts, its members at that time contribute to what it then does (Ludwig 2014a; 2017, ch. 5, sec. 2). Thus, [4] says that the 1954 members of the Court reversed the ruling of its 1896 members. No super agent is required.

Fourth, the fact that institutional membership is time indexed and socially constructed also explains how it is possible for the institution to have had different members (Ludwig 2014a; 2017, ch. 5, sec. 3). For it is possible for different individuals to have been assigned the relevant status. This no more requires an agent over and above its members than the fact that the president might have been someone else requires a super president to shadow the elected one (contra, e.g., Sheehy (2006)).

The explanation of (e) and (f) requires the concepts of a status function and a status role. First, we take up the concept of a convention, which we will employ in explaining status functions.

\subsection{Conventions}

'Convention' is used to express a number of related concepts. In one sense a convention is simply a custom, like what people wear, or whether they use chopsticks or forks. We focus on a narrower notion - which also concerned, e.g., Lewis in the classic (1969)—on which a convention rests on a (at least) tacit agreement in a group about how to solve a coordination problem. A simple example is a convention for driving on the right or left side 
of the road to avoid collisions. We want cars driving in opposite directions to consistently choose different sides. No one can solve the problem alone, so to solve it we must enter into a kind of agreement about which side to drive on. The problem is solved when everyone agrees to follow the same rule (idealizing a bit here). However, for this to be a genuine convention, more is required than that agents follow the same rule. This could happen even if each regards the others simply as states of nature in a strategic game. A convention is a solution to the problem that is understood as a joint solution. This happens when each member of the relevant group we-intends that whenever any of them are in the relevant sort of situation (driving with others on a public road), they act in accordance with the rule to drive, e.g., on the right (Jankovic 2011; 2014, ch. 6). This is a matter of them having appropriate conditional we-intentions to do their parts (realizing a tacit agreement). Conventions then are grounded in shared conditional intentions (Ludwig $2015 \mathrm{~b}$ ), which are a structure of conditional we-intentions of members of the group in which the convention is maintained.

\subsection{Status Functions and Roles}

A status function is assigned to objects, events, or persons (token or type) in social transactions. A status function is an agentive function. An agentive function is defined in relation to a use "to which agents intentionally put objects" (Searle 1995, p. 20), such as being a chair or a saw. What's special about status functions among agentive function is that they can perform their functions only in virtue of being collectively accepted as having them (Searle 1995, ch. 2). Examples are being a king in chess, a twenty-dollar bill, a royal seal, a judge, a ruling, or a border between countries. Thus, nothing can function as a twenty-dollar bill unless it is collectively accepted in the relevant community as a unit of exchange in monetary transactions. The physical characteristics are insufficient. In contrast, something with the right physical characteristics can saw a log in two, even if no one thinks of it as a saw.

How can collectively accepting something as having a certain function be crucial to its ability to perform the function? The answer is that the relevant function is defined in a way that leaves open what particular objects are to perform it (Ludwig 2014b; 2017, chs. 6-10).

The rules that determine the function are constitutive rules-rules the intentional following of which partially constitutes the type of activity they govern (Searle 1969). The rules of chess, for example, are constitutive rules. In contrast, Robert's Rules of Order are regulative rules because they govern a kind of activity that exists independently of the rules being followed.

The rules of chess define functions for certain objects in its play. For example, the white king belongs to the player who makes the first move. Positioned four squares from the right, it can be moved one square in any direction, if the square is not occupied by white's pieces, and not threatened by black's; it takes any opposing piece occupying the square. If it is in check and cannot move, black wins. 
While the rules define the role of the king, they do not fix what object is to be used in the role. Thus, two people who intend to play chess face a coordination problem. The solution consists in their accepting the same objects for the roles defined by the rules of chess. This coordination on particular things to play these roles is a convention, in the sense of the previous section. In the case of coordination on types to play roles in recurring social activities, collective acceptance amounts to adopting conditional we-intentions to use the relevant type of object in the roles in that activity type. Thus, a twenty-dollar bill has the status function it does because it is collectively accepted that things of its type are to be used in certain commercial transactions, even if it is never used.

A status role is a special sort of status function assigned to an agent where (a) the agent must be part of the group that collectively accepts the assignment, and (b) the function is partly defined in terms of how the agent in the role is to interact with other agents, events, and objects on the basis of their status roles and functions (Ludwig $2014 \mathrm{sec}$. 5; $2017 \mathrm{ch}$. 10). Examples are being a judge, policemen, senator, professor, student, and so on.

Thus, membership in an institution is a status role, and this provides a precise sense in which membership in an institution is socially constructed (Ludwig 2017, ch. 11).

\subsection{Institutions as networks of status roles}

We can define institutions as networks of status roles designed for coordinating joint intentional action for certain purposes by their possessors (Ludwig 2017, ch. 10-11). For example, to join the army is to be assigned (and to accept) a status function. Though it is presupposed that roles are occupied voluntarily, typically there will be provisions for how to treat someone who does not perform the duties associated with the role. In joining the army, one acquires the determinable status role of being soldier, and a determinate of that designated by rank and unit, as well as more specific status roles within organizations in the army. The effective functioning of the organization (its fulfilling the purposes for which it is designed) depends on enough of its members performing adequately in their roles visá-vis others. The roles in an organization are typically defined in terms both of how one is to interact with other members and how one is to interact with various non-members, since organizations typically have status roles in larger institutional settings. An organization can also assign status functions to others (without their acquiescence) to determine how its members are to treat them. For example, designating others as enemy soldiers or civilians assigns them status functions (though not status roles) that govern how they are to be treated.

The possibility of perpetual existence of institutions comes to the possibility of realization of the relevant organizational structures in successive (often overlapping) groups of agents. An institutional group may survive periods in which it lacks members when it has a place in a larger group. For example, the $22^{\text {nd }}$ regiment of the United States army was initially formed in the war of 1812, but disbanded and then reconstituted for the Indian wars of the 1860 s, and it has been disbanded and reconstituted a number of times since then. 


\subsection{Proxy Agency in Institutional Action}

A distinctive feature of institutional agency is the capacity to do things through authorized agents. We call these proxy agents (Ludwig 2014b). How does this work? Take the case of the spokesperson. Both groups and individuals can have spokespersons. This shows that proxy agency is not limited to groups. However, in both cases, the possibility of proxy agency relies on a background social agreement focusing on the spokesperson playing a role, by the exercise of her agency, in a social transaction between one person or group and others. Being a spokesperson then is a status role.

The key to proxy agency is authorization. Authorization is the assignment of a status role. We consider the simplest case in which members of the group, e.g., a club, designate a member by consensus to serve as spokesperson, and agree on what message the spokesperson is to convey. The purpose is to publicly commit the group to acting in accordance with the message. Both audience and group understand the exchange involving a spokesperson as their engaging in a joint intentional action. The audience's role is to recognize the spokesperson as acting under her authority to represent the group and attend to her message in that capacity.

The spokesperson's role is to produce an utterance act whose content is the message that the group aims to convey to its audience. The utterance act itself then has a status function in the transaction with the audience. The name for this status function is a group announcement. In this we borrow the language of speech acts applied to individuals, but its significance is different, because it is not an announcement of the spokesperson, and it is not in the ordinary sense a speech act by the group because the group does not have an intention to assert something in the way an individual does.

A conceptually necessary condition on the spokesperson's act counting as the group's announcing something is her being designated as their spokesperson. Thus, when the group announces something through a spokesperson, every member of the group contributes constitutively to the group announcement. In this way, even the phenomenon of proxy agency is brought under the multiple agents account of institutional agency.

This simple structure may be complicated along at least two dimensions (Ludwig 2016b).

First, the group can give more autonomy to the proxy agent. The proxy may be authorized, to decide on the specific way in which to convey a policy, to answer questions about it, or even to determine policy, or to make decisions that commit the group to various projects. In this way decision-making may be officially delegated to a subgroup or individual. The notion of a group decision here (like that of a group announcement) is constructed out of the social arrangements that give it content.

Second, the power to authorize individuals or subgroups to act as proxy agents for the group may also be assigned to a status role. The authorizations made by those proxies are then authorizations by the group by proxy. And this may extend through a chain of proxy agents. In more complicated cases, the constitutive contribution of many members of an 
organization may come to little more than their roles in constitutively sustaining the structure of the organization within which these authorizations are made and exercised. Yet, the basic conceptual structure remains the same.

\subsection{Social Norms and Status Functions}

There is an important connection between social norms (in one sense) and status functions and roles (Ludwig 2017 ch. 10, sec. 1-3). In the relevant sense of social norm, to violate a social norm is to make a mistake or to do something wrong internal to the type of social action the norm governs. For example, a policeman who makes a false arrest under the color of law has violated a norm internal to the type of action he undertakes.

How are social norms in this sense grounded in status functions? Things with status functions have associated norms determined by their role in the action type for which they are designed. There are three kinds. First, there are norms derived from the constitutive rules governing the action type. These define what has to be done for the action type to be instantiated. Thus, the rules of chess provide norms for chess. Second, there are norms derived from the conventions that attach functions defined by constitutive rules to particular objects, states or events. These are norms about what objects or types have functions in relevant social transactions. Third, there are norms that are derived from ideals for a type of action that can be instantiated without conforming to the ideal. For example, in many competitive sports there are expectations about how play is to go, violations of which are assigned a penalty. These rules provide norms for the activity, which are not constitutive, and not derived from conventions that attach status functions to particular objects, but rather are derived from a canonical conception of play. The canonical conception is a regulative ideal for play of the game. The same goes for many other types of essentially collective intentional action types. This extends to status roles. Status roles provide norms for their occupiers determined by their design function. These define the powers, rights and duties of the role players vis-à-vis others given their roles. For example, in a class, a professor has the power and duty to assign grades and the duty to do so on the basis of student performance. Students have a right to expect that grades are assigned fairly. This provides one sense in which social norms are constitutive of social institutions and practices. They may of course conflict with each other and with others sorts of norms, such as moral norms. This is illustrated by the case of a guard at a concentration camp.

\section{Collective Attitudes Other than Intention}

The practice of ascribing psychological attitudes to groups is not limited to intentions. Ascriptions of beliefs, desires, and emotions to groups are commonplace in everyday talk, as illustrated in [6]-[8].

[6] The Democratic Party believes that all Americans have the right to a fair wage.

[7] North Korea wants to sign a peace treaty with the United States.

[8] Russia is angry at Turkey. 
Moreover, many social-scientific and philosophical explanations involve irreducible appeal to collective attitudes. For example, rational choice theory has to appeal to the notion of common knowledge, because the strategic situation of agents in an interdependent choice is sensitive to whether they have common (or just mutual) knowledge of certain facts (Halpern 1986; Schelling 1960; Lewis 1969). More controversially, group guilt is invoked to account for the feelings of guilt that members of a group may harbor regarding a group action that they took no part in (Gilbert 1997).

The main issues in this area are analogous to those for collective intentions. There are psychological and ontological questions. The psychological questions concern the nature and structure of collective attitudes and their connection with states of individuals that constitute the relevant collectives. For example, common knowledge is initially glossed as knowledge that is public, and public knowledge is explained as knowledge a group has just in case everyone in the group knows that everyone knows (and so on ad infinitum) that something is the case (Lewis 1969). Is the regress involved conceptually problematic? Is it psychologically plausible that regular people would have such attitudes? Does the regressive formulation give the correct explication of the relevant notion of publicity?

The ontological questions concern the ontological commitments of ascriptions like [6]-[8], specifically, whether they commit us to group entities with genuine psychological states. The major groups of views concerning this issue are eliminativist, singularist (or individualist), and pluralist. (It might be thought that each of these has its appropriate context of application, but below we consider them as purporting to give a uniform account.)

Eliminativists reject all talk of group attitudes. They may consider ascriptions of psychological attitudes to groups to be false or metaphorical. These accounts have not been explored much, but some remarks by Quinton (1975) may be interpreted in this way.

Singularist accounts (the term is due to Gilbert $(1987,1989,2006))$ hold that collective attitude ascriptions are true, but consider them to be making claims about states of individuals, such as individual beliefs, desires, and intentions.

Eliminativist and singularist accounts are both compatible with methodological individualism, understood as the conjunction of the following two theses:

(1) We can understand and explain individual action on the basis of the individual's own attitudes and reasons (which may refer to other agents and their attitudes and reasons, and to reducible group attitudes and reasons) together with physical and nonsocial facts.

(2) Social ontology consists solely of the actions and activities of individuals and their relations and interactions, and reference to groups and group properties is reducible to the bases in (1) and (2). 
Within the singularist camp, we may distinguish between summative and non-summative accounts (following Quinton). Summative accounts hold that a logically necessary condition of the truth of an ascription of the form

$$
\text { Group } G \Psi \text {-s that } p \text { (or to } P \text { ) }
$$

is that

$$
\text { all (or most or enough) members of } G \psi \text { that } p \text { (or } \psi \text { to } P \text { ), }
$$

where $\psi$ is a propositional attitude verb, $p$ a sentence, $P$ a verb phrase. Call this condition the summation condition. For example, we might say the curriculum committee wants to change the distribution requirements only if all (or most or enough) members of the curriculum committee want to change the distribution requirements. Gilbert (1987) criticizes summative accounts that hold the appropriate summation condition to be both necessary and sufficient for the truth of the collective attitude ascription (Quinton 1975), as well as those that also require that it be common knowledge in the group that the summation condition holds; Corlett (2007) has responded to a number of Gilbert's criticisms.

Summative accounts of both kinds appear to be subject to counterexamples. First, they appear to be too weak. Suppose that each member of Congress believes that the minimum wage should be raised and that this is common knowledge, but that Congress has not taken a vote on the issue, and, for various reasons, is not going to do so. In this case, it would be odd to say that Congress believes that the minimum wage should be raised

Summative accounts also appear to be too strong. We can use the discursive dilemma (described by Pettit $(2001,2003,2007)$ ) to illustrate how it can appear that a group may believe/want/intend that $p$ even though none if its members believe/want/intend that $p$. (Schmitt (1994) gives a similar argument.) Suppose that a company (call it "All-for-Safety") is deciding whether to institute pay cuts in order to introduce several safety measures. For simplicity, suppose All-for-Safety is a cooperative so that the employees own it. The decision is made by the employees on the basis of three considerations: (1) whether the danger is serious enough to justify the cut; (2) whether the measures to be introduced are effective enough to justify the cut; (3) whether the employee can bear the pay sacrifice. Suppose that an individual employee will vote for the pay cut just in case she votes yes on all three considerations. The company may employ two decision procedures. It may employ a conclusion-centered procedure, which consists in aggregating individual employees' votes on whether they will take the pay cut. Or it may employ a premise-centered procedure, which consists in aggregating individual votes on the three considerations, and adopting the pay cut if the majority of the employees vote yes on each individual consideration. Suppose that Safety-First adopts a premise-centered approach and that the employees vote as follows. 


\begin{tabular}{|l|l|l|l|l|}
\hline & Dangerous & Effective & Bearable & Conclusion-centered \\
\hline $1 / 3^{\text {rd }}$ & Yes & Yes & No & No \\
\hline $1 / 3^{\text {rd }}$ & Yes & No & Yes & No \\
\hline $1 / 3^{\text {rd }}$ & No & Yes & Yes & No \\
\hline Premise-centered & Yes & Yes & Yes & Yes (P) $/$ No (C) \\
\hline
\end{tabular}

In this case, it appears that (9) is true and (10) false.

[9] All-for-Safety believes that the employees should accept a pay cut.

[10] All/most/some members of Safety-First believe that the employees should accept a pay cut.

One may reject summative accounts without rejecting singularism. For example, the discursive dilemma plausibly shows that a group belief ascription can be true when the corresponding summation conditions are false. If that's right, an ascription of a collective belief that $p$ cannot be reduced to some configuration of individual beliefs that $p$. But the individual intentional states to which an ascription of collective attitude reduces do not have to match the psychological mode and content of the collective attitude, as postulated by the summation condition. For example, one may hold that group $\mathrm{G}$ believes that $p$ if members of the group jointly accept the judgment-aggregating procedure according to which, if most members of the group believe $p$ and $q$, and $r$ follows from $p$ and $q$, then G believes $r$.

Finally, on pluralist accounts, collective attitude ascriptions cannot be understood solely using the concepts drawn from individual theory of mind and action. For example, (Gilbert 2006) explains collective attitudes (in general) in terms of the basic notion of joint commitment. In general, in joint commitment, we commit to holding a certain attitude as a body. For example, if we jointly commit to believing, as a body, that democracy is the best form of government, we collectively believe this. If we jointly commit as a body to feeling guilty about a certain action, we feel collective guilt over that action. And so on.

In contrast to eliminativist and singularist accounts, pluralist accounts are not compatible with methodological individualism.

Philosophers have discussed collective belief (Gilbert and Pilchman 2014; Gilbert 1987, 1989, 1994, 1996; Pettit 2003; List and Pettit 2011; Tollefsen 2007; Tuomela 1992; Schmitt 2016), collective memory (Wertsch 2009; Roediger and Abel 2015; Olick, VinitzkySeroussi, and Levy 2011; Michaelian and Sutton 2013; Hirst and Stone 2015), and collective moral attitudes such as guilt, pride, remorse, and shame (Gilbert 1997, 2002, 2001; Kutz 2000; May 1992; Tollefsen 2006), as well as collective emotions more generally (Huebner 2011; Wilson 2001).

\section{Summary and Conclusion}

Attributions of intentionality to collectives play a central role in our understanding of the social world. Our focus has been on collective intention and action. These are among the 
fundamental building blocks of the social world. They are implicated in our understanding of agreements, conventions, status functions, institutions, and social norms. We have suggested that collective intention and action rest on the capacity of individuals to form intentions with a distinctively cooperative content. An account of these we-intentions contributes not only to our understanding of the fundamental structure of the social world, but also of the capacities of mind that allow us to have the kinds of sociality we have. The self-conscious deployment of the concept of joint intentional activity patterns gives rise to the concept of a constitutive rule for social behavior, which prepares the way for the concepts of a status function, and of a status role, networks of which form the fabric of institutional reality. In addition to social ontology, the study of collective intentionality has implications on further areas of traditional interest to philosophers and social scientists such as cooperation, collective attitudes, responsibility, rationality, problem solving, attention, memory, and emotion. A further discussion of these and other topics can be found in (Jankovic and Ludwig 2016). 


\section{References}

Bratman, Michael. 1992. Shared Cooperative Activity. The Philosophical Review 101 (2):327-341.

- - 1993. Shared Intention. Ethics 104 (1):97-113.

- - . 1999a. I Intend that We J. In Faces of Intention: Selected Essays on Intention and Agency. Cambridge: Cambridge University Press.

- - . 1999b. Shared Intention and Mutual Obligation. In Faces of Intention: Selected Essays on Intention and Agency. Cambridge: Cambridge University Press.

- - 2 2006. Dynamics of Sociality. Midwest Studies in Philosophy: Shared Intentions and Collective Responsibility XXX: 1-15.

- - . 2014. Shared Agency: A Planning Theory of Acting Together. Oxford: Oxford University Press.

Chant, Sara, and Zachary Ernst. 2008. Epistemic Conditions for Collective Action. Mind 117 (467):549-573.

Copp, David. 2006. On the Agency of Certain Collective Entities: An Argument from 'Normative Autonomy'. Midwest Studies in Philosophy: Shared Intentions and Collective Responsibility XXX.

Corlett, J. Angelo. 2007. Analyzing Social Knowledge. Social Epistemology 21 (3):231-247.

Davidson, Donald. 2001. The Logical Form of Action Sentences. In Essays on Actions and Events. New York: Clarendon Press. Original edition, 1967.

Gilbert, Margaret. 1987. Modelling Collective Belief. Synthese 73:185-204.

- - . 1989. On Social Facts. London: Routledge.

- — . 1994. Remarks on Collective Belief. In Socializing Epistemology: The Social Dimensions of Knowledge, Schmitt, Frederick F (ed). Lanham: Rowman and Littlefield.

- - - 1996. Concerning Sociality: The Plural Subject as Paradigm. In The Mark of the Social, edited by J. Greenwood: Rowman and Littlefield.

- - . 1997. Group Wrongs and Guilt Feelings. Journal of Ethics 1 (1):65-84.

- - . 2001. Collective Remorse. In War Crimes and Collective Wrongdoing: A Reader. Maiden MA: Blackwell Publishing.

- - . 2002. Collective Guilt and Collective Guilt Feelings. Journal of Ethics 6 (2):115-143.

- - . 2006. A Theory of Political Obligation: Membership, Commitment, and the Bonds of Society. Oxford: Clarendon Press.

Gilbert, Margaret, and Daniel Pilchman. 2014. Belief, Acceptance, and What Happens in Groups. In Essays in Collective Epistemology, edited by J. Lackey: Oxford University Press.

Gold, Natalie, and Robert Sugden. 2007. Collective Intentions and Team Agency. Journal of Philosophy 103 (3):109-137.

Halpern, Joseph Y. 1986. Reasoning about Knowledge: An Overview. In Theoretical Aspects of Reasoning about Knowledge, edited by J. Y. Halpern. Los Altos, Calif.: M. Kaufmann Publishers.

Hirst, W., and C. B. Stone. 2015. A Unified Apporach to Collective Memory: Sociology, Psychology, and the Extended Mind. In Ashgate Research Companion to Memory Studies, edited by K. S. London: Ashgate.

Huebner, Bryce. 2011. Genuinely Collective Emotions. European Journal for Philosophy of Science 1 (1):89-118. 
Jankovic, Marija. 2011. The Intentional Underpinnings of Convention. In Pacific Division of the American Philosphical Association. San Diego, CA.

- - - 2014. Conventional Meaning. Dissertation, Philosophy, Indiana University. Jankovic, Marija, and Kirk Ludwig, eds. 2016. The Routledge Handbook on Collective Intentionality. New York: Routledge.

Kutz, Christopher. 2000. Complicity: Ethics and Law for a Collective Age. Cambridge: Cambridge University Press.

Lewis, David. 1969. Convention: A Philosophical Study. Cambridge: Harvard Univ Pr. List, Christian, and Philip Pettit. 2011. Group Agency: The Possibility, Design, and Status of Corporate Agents. Oxford Oxford University Press.

Ludwig, Kirk. 2007a. Collective Intentional Behavior from the Standpoint of Semantics. Nous 41 (3):355-393.

- - 2007b. Foundations of Social Reality in Collective Intentional Behavior. In Intentional Acts and Institutional Facts: Essays on John Searle's Social Ontology, edited by S. L. Tsohatzidis. Dordrecht: Springer.

- - 2010. Adverbs of Action. In Blackwell Companion to the Philosophy of Action, edited by T. O'Connor and C. Sandis. Oxford: Wiley-Blackwell.

- - . 2014a. The Ontology of Collective Action. In From Individual to Collective Intentionality, edited by S. Chant, F. Hindriks and G. Preyer. Oxford: Oxford University Press.

- - . 2014b. Proxy Agency in Collective Action. Nous 48 (1):75-105.

- - 2015a. Shared Agency in Modest Sociality. Journal of Social Ontology 1 (1):7-15.

- - - 2015b. What are Conditional Intentions? Methode: Analytic Perspectives 4 (6):3060.

——- 2016a. From Individual to Plural Agency: Collective Action I. 2 vols. Oxford: Oxford University Press.

- - . 2016b. Proxy Agency. In The Routledge Handbook on Collective Intentionality. New York: Routledge.

- - - 2017. From Plural to Institutional Agency: Collective Action II. 2 vols. Oxford: Oxford University Press.

May, L. 1992. Sharing responsibility. Chicago: University of Chicago Press.

Michaelian, Kourken, and John Sutton. 2013. Distributed Cognition and Memory Research: History and Current Directions. Review of Philosophy and Psychology 4 (1):1-24.

Miller, S. 2001. Social Action: A Teleological Account. Cambridge: Cambridge University Press.

Olick, J. K., Vered Vinitzky-Seroussi, and D. Levy, eds. 2011. The Collective Memory Reader. Oxford: Oxford University Press.

Pettit, Philip. 2001. Deliberative Democracy and the Discursive Dilemma. Nous-Supplement: Philosophical Issues 11:268-299.

- - . 2003. Groups with Minds of their Own. In Socializing Metaphysics, edited by F. Schmitt: Rowman and Littlefield.

——- 2007. Responsibility incorporated. Ethics 117 (2):171-201.

Quinton, A. 1975. Social Objects. Proceedings of the Aristotelian Society 75:67-87.

Roediger, H. L., and M. Abel. 2015. Collective Memory: A New Arena of Cognitive Study. Trends in Cognitive Sciences 19 (7):365-371.

Schelling, Thomas C. 1960. The strategy of conflict. Cambridge,: Harvard University Press. 
Schmitt, Fred. 2016. Collective Belief and Acceptance. In The Routledge Handbook on Collective Intentionality, edited by M. Jankovic and K. Ludwig. New York: Routledge.

Schmitt, Frederick F. 1994. The Justification of Group Beliefs. In Socializing Epistemology: The Social Dimensions of Knowledge, Schmitt, Frederick F (ed). Lanham: Rowman \& Littlefield.

Searle, John. 1969. Speech Acts: An Essay in the Philosophy of Language. London: Cambridge University Press.

- - 1990. Collective Intentions and Actions. In Intentions in Communication, edited by P. R. Cohen, J. Morgan and M. E. Pollack. Cambridge, Mass.: MIT Press.

- - 1 1995. The Construction of Social Reality. New York: Free Press.

- - . 2010. Making the Social World: The Structure of Human Civilization. Oxford: Oxford University Press.

Sheehy, Paul. 2006. The Reality of Social Groups, Ashgate new critical thinking in philosophy. Aldershot: Ashgate.

Stoutland, Frederick. 1997. Why are Philosophers of Action so Anti-Social? In Commonality and Particularity in Ethics, edited by Alanen, Heinamaa and Wallgreen. New York: St. Martin's Press.

- - - 2008. The Ontology of Social Agency. Analyse \& Kritik 30:533-551.

Tollefsen, Deborah. 2002. Collective Intentionality and the Social Sciences. Philosophy of the Social Sciences 32 (1):25-50.

- - . 2006. The Rationality of Collective Guilt. Midwest Studies in Philosophy 30 (1):222239.

- - . 2007. Group Testimony. Social Epistemology: A Journal of Knowledge, Culture, and Policy 21 (3):299-311.

Tuomela, Raimo. 1992. Group Beliefs. Synthese 91:285-318.

- - . 2005. We-Intentions Revisited. Philosophical Studies 125:327-369.

- - . 2013. Social Ontology: Collective Intentionality and Group Agents. New York, NY: Oxford University Press.

Tuomela, Raimo, and Kaarlo Miller. 1988. We-Intentions. Philosophical Studies 53 (3):367389.

Velleman, David. 1997. How to Share an Intention. Philosophy and Phenomenological Research 57 (1):29-49.

Wertsch, J. V. 2009. Collective Memory. In Memory in Mind and Culture, edited by P. Boyer and J. V. Wertsch. Cambridge: Cambridge University Press.

Wilson, Robert A. 2001. Group-Level Cognition. Philosophy of Science 68 (3):S262-S273. 